\title{
Educating for a Holistic View of the Earth System: A Review
}

\author{
Tiago Ribeiro ${ }^{1,2,3, *}$ and Nir Orion ${ }^{4}($ () \\ 1 Interdisciplinary Centre of Marine and Environmental Research (CIIMAR), Terminal de Cruzeiros de Leixões, \\ Av. General Norton de Matos s/n, 4450-208 Matosinhos, Portugal \\ 2 Faculty of Sciences (FCUP), University of Porto, Rua do Campo Alegre s/n, 4169-007 Porto, Portugal \\ 3 Universal Scientific Education and Research Network (USERN), Porto, Portugal \\ 4 Department of Science Teaching, Weizmann Institute of Science, Rehovot 76100, Israel; \\ nir.orion@weizmann.ac.il \\ * Correspondence: tiago.ribeiro@fc.up.pt
}

Citation: Ribeiro, T.; Orion, N. Educating for a Holistic View of the Earth System: A Review. Geosciences 2021, 11, 485. https://doi.org/ 10.3390/geosciences11120485

Academic Editors: Aberra Mogessie and Jesus Martinez-Frias

Received: 19 October 2021

Accepted: 17 November 2021

Published: 24 November 2021

Publisher's Note: MDPI stays neutral with regard to jurisdictional claims in published maps and institutional affiliations.

Copyright: (c) 2021 by the authors. Licensee MDPI, Basel, Switzerland. This article is an open access article distributed under the terms and conditions of the Creative Commons Attribution (CC BY) license (https:/ / creativecommons.org/licenses/by/ $4.0 /)$.

\begin{abstract}
The global society of today struggles with grand challenges, such as climate change, the degradation of ecosystems, and the loss of bio- and geodiversity, as identified in several documents. The search for solutions to these and other problems on the way to sustainable development necessarily involves a better understanding of the Earth system and its dynamics. The Earth system is composed of five highly dependent and interrelated subsystems that exchange matter and energy. This notion is at the base of what in the literature is named Earth System Science (ESS). Humanity has been profoundly altering the dynamics of this system, leading to the proposal of a new geological epoch-the Anthropocene. Developing a holistic understanding of the complex and tangled relationships between subsystems and the role of human impacts is the target of study of Earth System Education (ESE). With the assumptions of ESS, ESE is emerging as a new approach in science education. Based on a deep knowledge of the planet and the development of specific competencies, such as system thinking, it is possible to perform more actively and consciously in the relationships that citizens develop with the Earth system, enabling the existence of a more viable future for humanity.
\end{abstract}

Keywords: citizenship; Earth system education; Earth system science; sustainability

\section{Introduction}

Global society is dealing with urgent grand challenges related to environmental, economic, and social sustainability [1]. Society must be environmental, economic, and socially sustainable to guarantee the continuity of the human species without compromising future generations and planet dynamics [2,3]. This notion is reflected in the United Nations 2030 Agenda for Sustainable Development [4]. This document aims to find solutions for sustainable development through combined, coordinated, and articulated (re)actions between different nations to global problems (in environmental, economic, and social dimensions), considering the people, planet, prosperity, peace, and partnerships [4].

According to UNESCO, sustainable development " . . . is an organizing principle for global development that supports the well-being of both people and the planet" [2] (p. 3). This concept has expanded to bond the environmental, economic, and social aspects of sustainable development [2]. To guarantee the permanence of the human species on Earth, society must adapt to the planet's dynamics and its limited resources, minimizing its impacts [5]. One thing is clear, there is no Planet B [6] and contemporary society must reflect on the impacts of citizens' daily actions on Earth.

Studies and documents warn of the finitude of natural resources, the degradation of ecosystems, and climate change among other issues associated with the Anthropocene [7-9]. The Anthropocene links to the proposal of a new geological epoch by the Dutch chemist Paul Crutzen (1933-2021) during the International Geosphere-Biosphere Program (IGBP) meeting in Mexico in 2000 [10-12]. Crutzen argued that the intensification of the impacts of 
human activities has caused morphological and geological changes in the planet, especially following the industrial revolution in the second half of the 18th century, justifying the naming of this new geological epoch [13-15]. The beginning of this new era has been marked by an increase in the concentrations of methane and carbon dioxide trapped in polar ice, which matches with the invention of the steam engine by James Watt (1736-1819) in 1784 [15]. However, the designation of this new era does not yet have a consensus in the scientific community [10]. The word Anthropocene is based on the term Anthropozoic, coined by the Italian priest and geologist Antonio Stoppani (1824-1891) in 1873 who used it to state a new era $[11,13,14,16,17]$.

All these challenges facing Earth mentioned above, such as the overexploitation of natural resources, the degradation of ecosystems, and climate change, call for solutions to be addressed. However, these issues are complex and reflect and result from the Earth's own complexity as a system; to solve them, specific competencies and approaches are required. Thus, educating society about the Earth system is crucial for the daily life and future of humanity given the relationship between the human species and the planet $[1,18,19]$.

The Earth system is composed of five deeply interdependent and related subsystemsatmosphere, biosphere, cryosphere, geosphere, and hydrosphere-with constant trades of matter and energy $[18,19]$. This systemic notion of the Earth system's behavior is relatively recent, therefore its perception by the majority of citizens may not be a reality as it is not yet an applied approach in schools in many countries [3]. Investment in geosciences education is required for shifting the way citizens perceive the planet and its dynamics towards sustainability [5]. To this end, it is urgent to (re)think about how to teach and learn the (Earth) sciences and leave multidisciplinary paradigms to embrace inter- or transdisciplinarity - a trend that is already beginning to be observed $[18,20]$. The change to interor trans-disciplinarity could enrich the knowledge of the planet and shape our behavior towards it. Thus, more than ever, science education must develop the knowledge, skills, attitudes, and behaviors to guide us to global sustainability.

Respecting the complex and delicate dynamics of the planet is essential to promote sustainable development and guarantee humanity's survival, as well as the maintenance of the bio- and geodiversity of our planet. Nonetheless, to understand the close and intricate relationships between Earth subsystems and to realize the extent of anthropogenic impacts on the planet, it is necessary to develop several cognitive skills, such as system thinking $[18,21]$. The latter must be stimulated and developed through educational activities, and geosciences education may take on particular importance in this process due to the very characteristics of Earth sciences [5].

The geosciences is an interdisciplinary set of scientific branches that aim to study the planet, its structure, processes and phenomena, composition, and history, among other aspects [22]. The geosciences, also known as Earth sciences, includes a wide spectrum of disciplines, for example, astronomy, geochemistry, geology, geophysics, meteorology, oceanography, sedimentology, environmental science, or geography, among others [22-25], which includes diverse fields of natural sciences related to the study of the Earth. According to Frodeman [26], the term geosciences arises from a broad interpretation of what geology is, isolating itself from the idea that it is only the study of the solid aspect of the Earth, but rather an articulated and integrated study of air, water, soil, rock, ice, and biota elements. It is important to notice that there are several definitions of geosciences. In this work, the definition adopted views the geosciences as an interdisciplinary body of knowledge composed of several scientific branches.

Geoscientists, as professionals who practice the geosciences, may resort to system thinking to understand geological processes, phenomena, and the particularities of the planet that occur in different spatiotemporal scales [5], for which prediction and retrospection are extremely important [18]. 
In geosciences education, and following a perspective of inquiry-based learning, it is intended that students can become capable of replicating the work of geoscientists and develop scientific competencies specific to the geosciences, such as those mentioned above $[18,21]$. These scientific competencies, developed through geosciences education, are necessary for making conscious decisions toward the planet, for finding solutions to those grand challenges, and for active participation in society. In this work, the development of Earth System Science (ESS) and Earth System Education (ESE) and their connections with a holistic understanding of the planet and active citizenship are addressed. This is carried out to understand: (i) how ESS and ESE evolved and to establish relationships between them; (ii) how they can be transposed to everyday school life-making geosciences education more meaningful and promoting a holistic approach in geosciences teaching, inside and outside of the science classroom; and (iii) how a holistic approach can help in seeking solutions to the grand challenges that humans face today.

\section{Earth System Science (ESS): An Overview for a Holistic Understanding of Our Planet}

Earth System Science (ESS) is a transdisciplinary field that studies the structure and functioning of our planet in a systemic and holistic way, integrating its five adaptative subsystems-atmosphere, biosphere (and anthroposphere), cryosphere, geosphere, and hydrosphere [8,27,28]. Edwards and collaborators [29] consider that research in the scope of ESS is an approach that allows humanity to understand the brutality of the planetary crisis because it enables reflection on the anthropogenic impacts on Earth's dynamics.

ESS is a scientific area that merges knowledge from the geosciences, biology, chemistry, physics, and mathematics to interpret and predict the Earth system's complex behaviors [30]. According to Skinner and Murck [8], ESS obeys the scientific method based on observation and the collection of evidence that can be observed and/or tested. While it is a collective and iterative process, it does not necessarily follow all the steps of the method sequentially. However, not every process and phenomenon on Earth can be observed, tested, or reproduced in the laboratory due to their complexity and spatiotemporal scale. In this sense, the geosciences began to resort to modeling to explain, simulate, and predict these geological processes and phenomena-thus, adding an experimental component. The complexity of reproducing geological phenomena and processes in the laboratory and the difficulty in directly observing them due to their spatiotemporal dimension were an obstacle to the establishment and definition of Earth sciences as a science, especially when compared to the "hard" sciences, such as physics. Furthermore, its individualization as a science was further hampered by the fact that it is classified as a hermeneutic, historical, and field science [26].

From the perspective of ESS, the five subsystems are deeply related and share (i) matter among themselves, through geochemical and biogeochemical cycles, and (ii) the flow of energy [21,31]. Its (in)stability depends on the dynamic interactions and non-linear feedback processes (positive and negative) that make the Earth system function as a whole $[5,18,21,30,32]$. Several authors, such as Orion [18], Steffen and collaborators [27], and Mayer [33], uphold that the planet is a complex and adaptive single system. An action in one of the subsystems can trigger one or more repercussions in others to maintain the overall system's dynamic stability $[29,31]$.

The development of ESS is necessarily related to a systemic notion of the planet. To understand this idea, it is necessary to identify the elements that comprise the system and their relationships according to its framework. Biogeochemical cycles correspond to interrelations with elements of several subsystems that are essential for the functioning of the planet as a whole. According to Jacobson, Charlson, and Rodhe [34], in the 18th century the Scottish geologist, chemist, and naturalist James Hutton (1726-1797) considered that the Earth behaves like a superorganism, and that it should be studied with the enlightenment of physiology. From this idea, it is understood that the planet is composed of several subsystems, similar to how the human body is formed by various organ systems (such as the circulatory or digestive systems, for example), and that our understanding of the 
Earth is possible through a study of the physical and chemical mechanisms that underlie it-such as biogeochemical cycles. These cycles result from the interaction of the biotic (biosphere) and abiotic (atmosphere, cryosphere, geosphere, and hydrosphere) aspects in the recycling of the planet's matter, which evidence the relationships between Earth's subsystems (understanding the cyclic nature of the system).

ESS has its roots in the biosphere and geosphere interaction analysis of the Russian geochemist and mineralogist Vladimir Vernadsky (1863-1945), where living beings were the geological force that shaped the Earth [30,34,35]. However, when his work "The Biosphere" was published in 1926, it did not receive the recognition it deserved since it was written in Russian. Only later, in 1998, was it translated into English, provoking interest among western scientists [36]. Meanwhile, in the field of climatology, in 1956 (20th century) the American scientist Eunice Newton Foote (1819-1888) described the influence of the concentration of water vapor and carbon dioxide on the retention of solar energy through heat, explaining its greenhouse effect [37]. Through her work, Foote highlighted the relationship between the concentration of these gases and the flow of solar energy, explaining their role in the climate system as resulting from the relationship between the Earth's subsystems.

Vernadsky's work was the basis for the Gaia hypothesis by James Lovelock (1919-) and Lynn Margulis (1938-2011) in the second half of the 20th century-biotic and abiotic components form a self-regulated system that maintains the composition of the atmosphere and climate for the planet's habitability — and this was the starting point of ESS [28,30,38-40]. Both Vernadsky's and Lovelock and Margulis' hypotheses emphasize two important aspects for ESS: (i) the notion that there are interactions between different Earth subsystems (such as the biosphere and geosphere) and (ii) the idea that the planet behaves like a self-regulated system.

The formal and explicit ESS appearance is linked to (i) the socio-political context of the Cold War, (ii) the greater funding of Earth and environmental sciences, and (iii) the beginning (during the 1960s-1980s) of the scientific community and general public environmental awareness $[27,30]$.

According to Steffen and collaborators [27], ESS is a result of increased awareness of climate change and ozone depletion and is a response to a sequence of reports from conferences and workshops called "science of the Earth", formalized by the creation of the NASA Earth System Science Committee in 1983. Then followed the first representation of the systems' dynamics (the NASA Bretherton diagram), in which the physical climate system is combined with biogeochemical cycles, including human, and interrelated by feedback mechanisms $[25,28]$. Humanity was seen as a driving force for changing the system-as an element producer of carbon dioxide, polluting emissions, and as a user of the land - thus placing humans as an integrant and important part of Earth system [27,30,41,42]. This representation led to emphasizing the perspective of understanding the interactions of the Earth system between physical, chemical, and biological processes, combining different disciplines for its study, and accelerating the evolution and globalization of ESS [27].

The significant change that makes ESS emerge-and that guides its theoretical frameworkis the conception of system thinking; this is instead of a traditionalist approach in which processes/phenomena are studied in isolation [8,27]. In this way, ESS demarcates itself from reductionist approaches [43].

At the end of the 1990s, two concepts that would become essential for ESS were introduced: (i) the dynamic and co-evolutionary relationship between human beings and the Earth system on a planetary scale (entirely integrating humanity into the Earth system); and (ii) the possibility of catastrophe in the co-evolutionary human domain of the Earth system (human pressures could trigger rapid and irreversible changes in the Earth system in states that would be catastrophic for human well-being) [27].

In the 2000s, the concepts of sustainability science and global sustainability emerged reflecting on the evolution of the definition of ESS [27], and due to the anthropic impacts on the Earth system, the terms Anthropocene and anthroposphere additionally appeared [8]. According to Skinner and Murck [8], the anthroposphere includes the human population, 
the artificial environment, and all other remaining parts in which the Earth system has been altered or manipulated by human actions. These anthropic impacts have become more evident in the last century [44]. However, Donges and collaborators [45] argue that the impact of the human domain is not yet fully integrated into current Earth system models and the exact feedback of the Anthropocene is not circumspect, with the social component being subjugated. These authors also warn that the norms and values that shape human behaviors cause changes in the Earth system's functioning. This also causes feedbacks in human behaviors, values, and norms by being a very complex co-evolutionary network. Thus, ESS evolves not only as an area of the natural sciences, but also integrates the social sciences [46,47]. Oreskes [48] argues that in various fields of research in the Earth sciences, such as seismology or volcanology, aspects related to human behaviors, institutions, infrastructures, and human responses are included. Furthermore, the same author adds that, although the geosciences have social implications, only recently have they been recognized in the research in these scientific fields. This fact indicates the need to link geosciences and social sciences, integrating the human species and its dynamics as elements to be considered in scientific research and helping to develop more holistic approaches to the research process. Given the particularities of geosciences and social sciences, they present distinct paradigms, objects of study, and research methodologies. Considering the systemic view of ESS and the fact that human actions and dynamics impact and are impacted by the Earth system, it is necessary to converge these areas. This may help create a more complete and realistic approach to the interrelationships between the subsystems, which includes humans. As natural and social systems are not dissociable, this translates into the emergence of interdisciplinary areas of study, such as geopolitics or geoethics (discussed later), for example. The integration of natural sciences with social sciences makes it possible to address environmental, social, economic, and political aspects, which is essential for a more effective response to global challenges.

The research spectrum in ESS is large. It starts with knowledge of the Earth's history passing through to the understanding of its present, its future perspectives, and its finitude [30]. According to Lenton, ESS “... considers how a world in which humans could evolve was created, how as a species we are now reshaping that world, and what a sustainable future for humanity within the Earth system might look like" [30] (p. 21). Reid and collaborators further argue that "research is also needed to assess the potential impact of environmental changes on regional economic conditions, food security, water supplies, health, biodiversity, and energy security" [46] (p. 196), highlighting the role of ESS in multiple domains.

Given the above, an understanding of the Earth system must be articulated with the complexity of the feedback processes in various domains, such as environmental and anthropogenic, among others. This integration of concepts and their relationships is essential for the development of more accurate models of the Earth system and its functioning [47]; this would allow for a recognition of its holistic nature, making it possible to forecast and retrospect different phenomena/processes, both in time and space. For such an understanding, it is necessary to develop holistic and system thinking to develop closer notions of the Earth's processes and dynamics. According to Hoffman and Barstow, understanding the interconnections between Earth's subsystems is essential for the future of nations and the planet because, for example, changes in the oceans and atmospheric processes impact "national economies, agricultural production patterns, severe weather events, biodiversity patterns, and human geography" [47] (p. 9). This notion is essential for understanding that the sustainable use of the planet depends on citizens' knowledge of it and of how the planet works.

Greater knowledge of the Earth system, from ordinary citizens to decision makers, can provide better responses to the challenges-societal, environmental, and economic - that humanity faces. As global sustainability cannot be addressed without considering global dynamics and interactions, more research in the field of ESS [46] is required. Thus, ESS is currently a scientific area in full development and consolidation. 


\section{Earth System Education (ESE): A Paradigm Shift in Geosciences Education}

Geosciences education has developed and evolved over past centuries, especially during the 1990s [31]. At the end of the 20th century, the abandonment of transmissive teaching methodologies and strategies (based on instructive theories) by moving to inquirybased teaching methodologies (embracing the constructivist and social constructivist theories) began. These students centered and oriented methodologies, respect learners idiosyncrasies, and shifted the paradigm from preparing future scientists to educating future citizens $[21,31,49,50]$. These last notions focused attention to learners' previous knowledge and experiences and their relationship with the environment. This occurs by exposing the students to meaningful and attractive environmental issues, such as pollution, climate change, or even flood events, earthquakes, or volcanic eruptions, to contextualize the learning process [31].

From a conceptual point of view, this paradigm shift led to the inclusion of environmental issues in the sciences curriculum. However, this was without great success because the approaches did not integrate the students' knowledge of the environment, thus falling into smaller activities such as recycling [21]. In this sense, according to Orion [31] a change to the Earth system approach as a holistic framework for science curricula was imperative. This approach would meet the Lovelock and Margulis hypothesis as Lovelock proposed that environmental research should reject reductionist approaches, developing a multidimensional perspective closer to reality and providing a global view of the Earth system [31].

From an interpersonal perspective, an ESE approach allows the ability to reach myriad moments for social interaction. This depends on the social capacity of learners, the way they interact with their peers in the learning process, and the ability of teachers to promote this social aspect [18].

From a disciplinary perspective there has also been an evolution, with interdisciplinary rather than multidisciplinary approaches being adopted [20]. In geosciences education in particular, the dissociation of different Earth sciences does not make any sense considering the complexity of the planet, as discussed in the previous section.

The conceptual development of ESS, associated with the influence of science at the end of the Cold War and the low level of scientific literacy of citizens about the planet, led to the emergence of the appropriate context at the end of the 20th century to draft the first curricula based on the Earth system approach [33,51]. According to Mayer [33], this movement began in secondary curricula in the United States of America (USA) and resulted from reflection on the science and the science curriculum in the post-war period and its influence on the planet and society. This approach started from discussing environmental problems-such as global warming, ozone depletion, and the degradation of water and land resources- to social issues resulting from the conflict. At this point, the new science curriculum needed to reject the rigid barriers between sciences, mathematics, and technology, creating synergies between them $[33,47]$.

In April 1988, after a five-day conference that brought together geoscientists and educators, including those responsible for the Bretherton Report, the initial theoretical framework of Earth sciences concepts that citizens were recommended to know was created [33,52]. This movement started a discussion, both regionally and nationally, of these issues, which drove the appearance of Earth System Education (ESE), later consolidated at The Ohio State University (USA) [33,51].

\subsection{Earth System Education (ESE) in Indoor and Outdoor Learning Environments}

As previously mentioned, with the appearance of ESS a new approach to teaching and learning geosciences was developed-Earth System Education (ESE). ESE is based on the assumptions of ESS, since the dynamics of the planet are studied holistically. Thus, the Earth is seen as a unique and adaptive system composed of five subsystems. These subsystems exchange energy and matter through geochemical and biogeochemical cycles- 
such as the rock cycle, water cycle, food chain, and carbon cycle-with each other, in which human actions are integrated $[18,27,53,54]$.

An ESE approach requires the development of competencies-knowledge, skills, and attitudes-specific to geosciences, such as the development of system thinking with a high level of abstraction, the retrospection and prediction of geological phenomena/processes, and a comprehension of these in diverse space-time scales [18]. In the context of ESE, the development of system thinking is essential as the educational effectiveness of this approach depends on the presence of this type of thinking [21].

According to Soltis and collaborators [55], system thinking corresponds to the understanding of how individual systems and their subsystems respond and relate to each other indissolubly based on the circular nature of their interactions in the real world. Kioupi and Voulvoulis [1] argue that socio-economic subsystems must also be taken into account and that interdisciplinary collaboration is essential for a holistic conception of reality. BenZvi-Assaraf and Orion [21] argue that system thinking is a form of reasoning necessary for understanding the social, technological, and scientific domains in parallel with environmental insight. Orion [18] defines environmental insight as the ability to overcome cognitive conflicts in the development of system thinking and the integration of diverse concepts through the understanding of phenomena with different spatiotemporal scales. Thus, a system is much more than the cumulative outcome of its parts, rather it is the result of these parts and their relationships [55]. The literature reveals that the maximum level of understanding of the Earth system is the ability to think about the planet as a dynamic system. However, studies show that students have great difficulties at this level $[25,55]$.

According to Ben-Zvi-Assaraf and Orion [56], the development of systems thinking depends on eight abilities, organized hierarchically. These authors refer that these abilities as the System Thinking Hierarchical (STH) model and comprising: (i) the identification of the elements of a system and processes that happen inside it; (ii) the recognition of the interrelationships between the various parts of the system; (iii) the identification of the system's dynamic relationships; (iv) the organization of the different elements and processes of the systems according to their relationships' framework; (v) the understanding of the cyclic nature of systems; (vi) generalization; (vii) the comprehension of the system's patterns and interrelationships that do not occur on the surface and therefore are not perceptible; (viii) the ability to retrospect and predict the system's processes [56].

Regarding the main difficulties present in learning the Earth system, the following stand out: (i) the need for comprehension of the planet as a dynamic system; (ii) the inability of viewing the Earth as a single system instead of disconnected parts; (iii) the inadequate mental models about Earth subsystems; and (iv) the lack of intuitive and complex conceptual knowledge about causality and mechanisms [43]. These difficulties are further increased when pondering the diversity of space and time scales of Earth system phenomena.

Orion [31] upholds that an ESE approach must focus on three important aspects: (i) it must be contextualized and be relevant to the daily lives of students; (ii) it must develop environmental insight; (iii) it must be based on a constructivist approach. An essential component of the ESE holistic pedagogy is the integration of learning environments. This integrates indoor environments (classroom, laboratory, and computer) and outdoor teaching environments [18].

Field trips are educational approaches that are especially important in the Earth and life sciences. Fieldwork has been recognized by researchers as a method for studying the natural world. However, it is still poorly present in daily school life due to logistical limitations, the lack of adequate educational resources, and teachers' unpreparedness concerning outdoor learning environments. Notwithstanding, the same author argues that field trips have positive learning outcomes when combined with indoor activities, functioning as an intermediary element for greater levels of cognitive learning. The outdoor environment provides the direct contact between what is learned in the classroom or laboratory with real phenomena/processes and materials, constituting a true sensorimotor experience [57]. 
Orion [57] suggests a tested and inquiry-based practical model for the integration of the outdoor teaching environment as an integral part of the learning sequence $[57,58]$. This model includes three consecutive stages: (i) the preparatory unit (in the classroom and/or laboratory-indoor environment); (ii) the field trip (outdoor environment); (iii) the summary unit (in the classroom-indoor environment) $[53,56]$ (Figure 1 ). This model fits into a student-centered perspective in which the students participate as active epistemological agents of their learning process, and enables a student's direct relationship with the environment rather than the passive acquisition of knowledge from teacher to student. This direct interaction with concrete Earth system's phenomena stimulates their natural learning instinct, and, as a result, their positive emotions and motivation to learn [59].
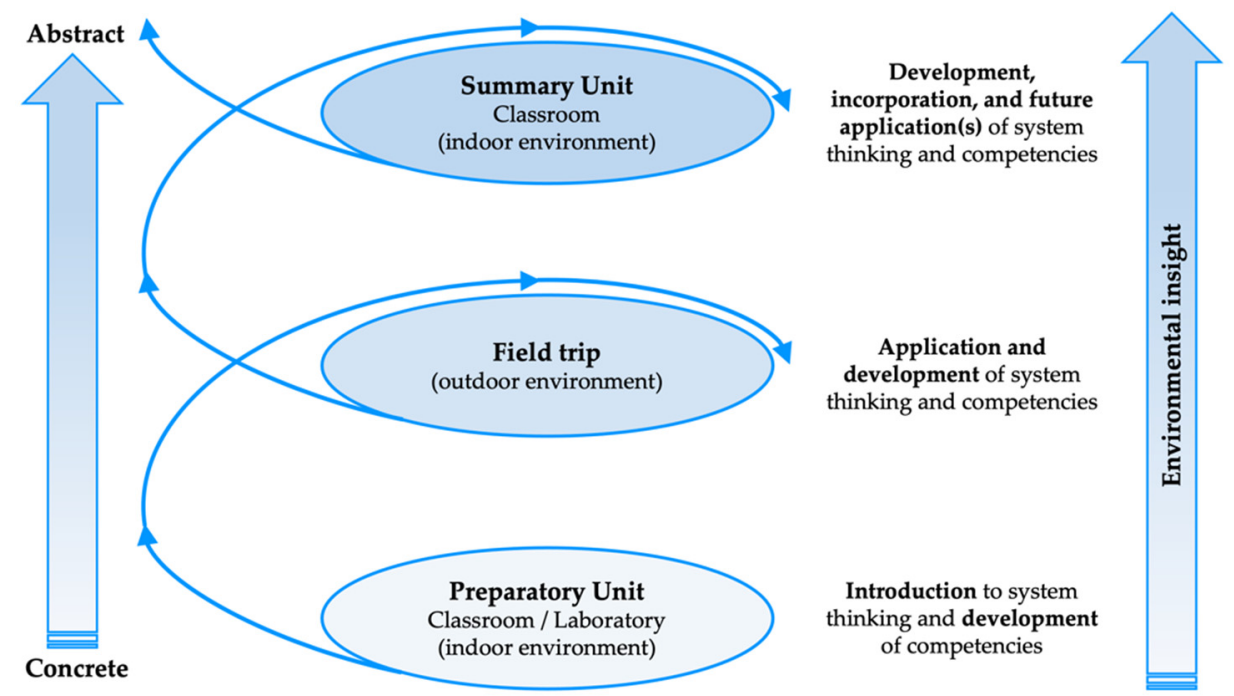

Figure 1. Orion's field trip model with the integration of system thinking and environmental insight development (adapted from Orion [57] (p. 329)).

The preparatory unit is based on lab inquiry-based activities of topics to be addressed in the field (such as modeling activities or managing the materials that students will contact on the field trip, such as rock and minerals, by using identifying skills). The operationalization of these tasks allows for developing concepts in concrete subjects, while introducing students to the next phase (field trip), taking care of cognitive, psychological, and geographic factors, reducing the novelty of space [57-59]. Cognitive aspects can be addressed through the manipulation of samples and materials that students will come into contact with on the field trip, worksheets, or a review of theoretical concepts before the field trip. Psychological aspects can be reduced by explaining the field trip objectives, the activities to be developed, or the stops to be made. Geographical factors can be minimized by handing out maps of where the field trip will take place, even using technologies such as GIS (which makes it possible to trace how natural systems function and change in response to anthropogenic activities by allowing the integration of environmental data at different temporal and spatial scales [60]), for example.

Learning during field trips is more significant when novelty space is reduced to a minimum [59]. In the field trip, the competencies developed in the previous unit are integrated with the elements of the natural world, applying system thinking to real examples and increasing the level of abstraction [57]. To this end, the field activity should provide students with contact with the natural world through the observation of geomorphological and lithological aspects and/or interactions between the different subsystems.

Finally, in the summary unit the activities to consolidate the competencies developed abroad in the form of multiple intelligences are completed, raising the level of abstraction with the application of knowledge to new situations [57] (Figure 1). 


\subsection{Environmental Insight and System Thinking}

A necessary component for achieving the goal of the ESE approach (environmental insight) is system thinking ability. The development of system thinking is intended and endowed with a high level of abstraction, making learners capable of interrelating concepts [18]. The literature states that environmental insight results from a combination of three factors: (i) recognize that we live on a planet in which subsystems interact cyclically through the exchange of matter and energy; (ii) understand that humanity is part of the Earth system, and iii) live in line with its dynamics [18,19,54].

Coexisting with Earth dynamics is a fundamental step for society to prosper because it is the planet that rules our existence, and not the opposite. Human behaviors affect the dynamic balance of the planet, but even without our presence it will continue its natural process of evolution. The best approach to reach a good level of coexistence with the Earth is to educate citizens about how it works. Thus, learning about the Earth system is part of the path that society has to take for our survival as a species. Therefore, it is interesting to know the mechanisms underlying the human learning process about the Earth system.

Learning is a natural process corresponding to the instinctive response to stimuli and is dependent on the individual $[18,19,59]$. The need to survive, combined with the curiosity to learn and the human tendency to pursue new challenges, means that the main stimulus for learning is emotional, and cognitive capability follows this emotional need $[18,19,59]$.

An ESE approach allows learners to attach meaning to what they learn, establishing a nexus between what is learned and the real world [18]. By assigning relevance to what is learned, stimuli for their learning instinct might be triggered $[18,19]$. Additionally, these stimuli might support the learners to move into inquiry-based learning [18]. The connection with the real world is even more effective when an ESE approach includes outdoor activities, such as field trips [18]. Research on the affective domain in Earth science suggests that learners have positive feelings about field activities before leaving the field, and this is even more evident after these activities [59]. This process, when scaffolded by the right methodologies, strategies, and resources, allows learners to profoundly develop their thinking. This makes it possible to articulate, for example, system, cyclic, logic, three-dimensional, or spatiotemporal thinking $[18,19]$.

\section{Educating Geosciences through a Holistic Approach for an Active Citizenship}

Never so much as today has the human relationship within the planet been so discussed and gone beyond academic discussion inside the scientific community; climate change and resource efficiency and management have become hot topics in society. Today more than ever, for society to move towards sustainability, changes in knowledge, values, attitudes, and behaviors are needed, both individual and collectively [1].

The reflection on the dynamics of the Earth system must include social and economic aspects because the human being is an integral part of the system. Reflecting on the impact of human actions on the planet is the object of study in geoethics. Geoethics is a recent scientific area that deals with the ethical, social, economic, and geoscientific aspects of human interactions with the Earth system, contributing to a more contextualized and efficient awareness of society on planetary and human sustainability. Teaching and learning geoethics largely contributes to raising citizens' awareness of environmental, social, and economic impacts [61]. Citizens must be aware of how they relate, act, and think towards biotic and abiotic systems that comprise the Earth $[1,18,62]$, recognizing that human-Earth system interactions are quite complex. To unravel this complexity, citizens must develop system thinking. An active citizenship that addresses issues relating to the planet in an interdisciplinary way is urgently required and must reflect on the social, economic, and environmental domains of human actions and their impacts.

In literature, the term environmental citizenship appears, and this is an interdisciplinary concept that integrates several areas, such as science, economics, philosophy, and politics [63]. This concept is recognized as an important approach to environmental problems, contributing to increasing the public pressure, such as through petitions, to trigger 
political actions, and science and environmental education has a particular role to play [63]. Environmental citizenship is often understood as green citizenship, ecological citizenship, or sustainability citizenship as there is no clear distinction between these terms [63]. In this context, education emerges as a powerful tool, capable of contributing to the behavioral changes in citizens $[1,63]$, although environmental citizenship is not yet fully present in educational practice [62].

Environmental citizenship merges the contributions of science education, environmental education, education for sustainability, and citizenship education [63]. An environmental citizen is defined as a citizen who has adequate knowledge, as well as the necessary values, attitudes, and skills, which allow them to act in society as an agent of change with the objective of solving environmental issues and achieving sustainability [63]. For this, an environmental citizen must have critical thinking, good communication skills, and the determination to participate [62].

The literature reveals that science education has a key role in supporting active and responsible citizenship where citizens get involved in the decision making regarding socio-scientific and socio-technical issues [63]. Parra and collaborators [62] argue that environmental education aims to obtain knowledge and develop the human-Earth system relationship through active learning experiences, such as fieldwork and outdoor activities. In this way, the importance of field trips in the scope of ESE is highlighted. Thus, the development of competencies by citizens in the field of Earth sciences (where environmental issues can be addressed through geosciences education) makes them capable of deciding policies or electing someone with this ability $[1,18]$, thus raising collective awareness of the grand challenges that humanity faces. This awareness can be achieved through a proper geosciences education (and communication) because to live in harmony with the environment, society must be environmentally literate and understand its influence on the Earth system $[18,19]$. Geosciences education is a crucial area for increasing scientific literacy and sustainable development, being a field permeable to multiple teaching methodologies and strategies inside and outside of the science classroom (see Vasconcelos [64]).

A holistic approach to geosciences education such as ESE has particular relevance as its aim is to provide citizens with competencies and make them recognize that they must live peacefully with the Earth system dynamics and achieve environmental insight [18]. Education as a social science, and in its different features-formal, non-formal, and informalplays an important role in public awareness and in the training of future citizens who should embrace this movement [65]. Furthermore, society must not neglect the role of lifelong education to educate and update older citizens or those who have not had opportunities in formal education $[4,65]$, keeping them active for their participation in society. According to Akin and Calik [66], keeping citizens involved in public life is important for the achievement of an advanced and democratic society.

\section{Final Remarks}

To face the grand challenges of today, actions are required to fulfill the United Nations Agenda 2030 for Sustainable Development. Understanding the Earth system contributes to the achievement of several goals of this document because one of the pivots of this agenda is the planet itself and the promotion of planetary sustainability. The latter requires a transdisciplinary approach, such as ESS, where the natural and social sciences create synergies to solve contemporary problems. To guide anthropic actions towards the planet, it is necessary to develop a holistic notion of the Earth. Through an understanding of the Earth system and how it works, it is possible to perceive the magnitude of human impacts. A society that holds this notion is a society better prepared to reflect on its knowledge, values, attitudes, and behaviors.

In this sense, ESE, with the incorporation of outdoor activities, enables the articulation between the development of knowledge and competencies and the direct contact with real-world phenomena, enabling a cognitive conflict and stimulating the learning processes. Additionally, this approach allows for a deeper recognition of the Earth system dynamics. 
The development of system thinking associated with environmental insight allows learners to understand how their actions, choices, and behaviors can affect the dynamism of the planet. The awareness of citizens on this issue enables more active and aware participation in society concerning the human-Earth system interactions towards sustainability. Thus, the change in the educational paradigm of ESE is justified. Investment for its inclusion both in the curriculum and in non-formal and lifelong education activities is imperative for fostering a holistic view of the Earth among the citizens.

Author Contributions: Conceptualization, N.O. and T.R.; writing-original draft preparation, T.R.; writing-review and editing, N.O. and T.R.; supervision, N.O. All authors have read and agreed to the published version of the manuscript.

Funding: This research was supported by (i) the Portuguese National Funding Agency for Science, Research, and Technology (FCT), through a Ph.D. Scholarship_-“An approach to the Earth system from a geoethics perspective: from science education to citizen science" (ref. SFRH/BD/143306/2019) and (ii) the Strategic Funding ref. UIDB/04423/2020 and ref. UIDP/04423/2020, through national funds provided by FCT.

Data Availability Statement: Not applicable.

Conflicts of Interest: The authors declare no conflict of interest.

\section{References}

1. Kioupi, V.; Voulvoulis, N. Education for Sustainable Development: A Systemic Framework for Connecting the SDGs to Educational Outcomes. Sustainability 2019, 11, 6104. [CrossRef]

2. United Nations Educational, Scientific and Cultural Organization (UNESCO). Education for People and Planet: Creating Sustainable Futures for All, 2nd ed.; UNESCO Publishing: Paris, France, 2016.

3. Vasconcelos, C.; Ferreira, F.; Rolo, A.; Moreira, B.; Melo, M. Improved concept map-based teaching to promote a holistic earth system view. Geoscience 2020, 10, 8. [CrossRef]

4. Transforming Our World: The 2030 Agenda for Sustainable Development (A/RES/70/1). Available online: http://www.un.org/ ga/search/view_doc.asp?symbol=A/RES/70/1\&Lang=E (accessed on 1 June 2021).

5. Vasconcelos, C.; Orion, N. Earth science education as a key component of education for sustainability. Sustainability 2021, 13, 1316. [CrossRef]

6. Berners-Lee, M. There is no Planet B: A Handbook for the Make or Break Years; Cambridge University Press: Cambridge, UK, 2021.

7. Ehlers, E.; Krafft, T. Earth System Science in the Anthropocene; Springer: Berlin, Germany, 2006. [CrossRef]

8. Skinner, B.J.; Murck, B.W. The Blue Planet: An Introduction to Earth System Science; John Wiley \& Sons: Hoboken, NJ, USA, 2011.

9. Smith, P.; Howden, M.; Krug, T.; Masson-Delmotte, V.; Mbow, H.O.P.; Reisinger, A.; Canadell, J.; O’Brien, P. Special Report on Climate Change, Desertification, Land Degradation, Sustainable Land Management, Food Security, and Greenhouse Gas Fluxes in Terrestrial Ecosystems (SR2); IPCC: London, UK, 2017.

10. Carruthers, J. The Anthropocene. S. Afr. J. Sci. 2019, 115, 1. [CrossRef]

11. Turpin, E.; Federighi, V. A new element, a new force, a new input: Antonio Stoppani's Anthropozoic. In Making the Geologic Now; Ellsworth, E., Kruse, J., Eds.; Punctum Books: Brooklyn, NY, USA, 2012; pp. 34-41.

12. Steffen, W. Introducing the Anthropocene: The human epoch. Ambio 2021, 50, 1784-1787. [CrossRef] [PubMed]

13. Crutzen, P.J. Geology of mankind. Nature 2002, 415, 23. [CrossRef] [PubMed]

14. Crutzen, P.J. The "anthropocene". J. Phys. 2002, 12, 1-5. [CrossRef]

15. Steffen, W.; Crutzen, P.; McNeill, J. The Anthropocene: Are Humans Now Overwhelming the Great Forces of Nature. In Environment and Society: A Reader; Schlottmann, C., Jamieson, D., Jerolmack, C., Rademacher, A., Eds.; New York University Press: New York, NY, USA, 2017; pp. 12-31. [CrossRef]

16. Bobrowsky, P.; Cronin, V.S.; Di Capua, G.; Kieffer, S.W.; Peppoloni, S. The emerging field of Geoethics. In Scientific Integrity and Ethics in the Geosciences; Gundersen, L.C., Ed.; John Wiley \& Sons: Hoboken, NJ, USA, 2018; pp. 175-212. [CrossRef]

17. Lucchesi, S. Geosciences at the service of society: The path traced by Antonio Stoppani. Ann. Geophys 2017, 60, 1-7. [CrossRef]

18. Orion, N. The future challenge of Earth science education research. Discip. Interdscip. Sci. Educ. Res. 2019, 1, 3. [CrossRef]

19. Orion, N. The relevance of earth science for informed citizenship: Its potential and fulfillment. In Contextualizing Teaching to Improving Learning: The Case of Science and Geography; Leite, L., Dourado, L., Afonso, A., Morgado, S., Eds.; Nova Science Publishers: New York, NY, USA, 2007; pp. 41-56.

20. Klaassen, R.G. Interdisciplinary education: A case study. Eur. J. Eng. Educ. 2018, 43, 842-859. [CrossRef]

21. Ben-Zvi-Assaraf, O.; Orion, N. Development of system thinking skills in the context of earth system education. J. Res. Sci. Teach. 2005, 42, 518-560. [CrossRef]

22. Kleinhans, M.G.; Buskes, C.J.; de Regt, H.W. Philosophy of Earth Science. In Philosophies of the Sciences: A Guide; Allhoff, F., Ed.; John Wiley \& Sons: Hoboken, NJ, USA, 2010; pp. 289-317. [CrossRef] 
23. Bokulich, A.; Oreskes, N. Models in Geosciences. In Springer Handbook of Model-Based Science; Magnani, L., Bertolotti, T., Eds.; Springer International Publishing: Basel, Switzerland, 2017; pp. 891-911. [CrossRef]

24. Hooijberg, M. Dealing with Geoscience Branches. In Geometrical Geodesy; Hooijberg, M., Ed.; Springer: Berlin, Germany, 2008; pp. 27-35. [CrossRef]

25. Johnson, D.R.; Ruzek, M.; Kalb, M. What is Earth system science? In Proceedings of the 1997 IEEE International Geoscience and Remote Sensing Symposium Proceedings. Remote Sensing-A Scientific Vision for Sustainable Development (IGARSS'97), Singapore, 3-8 August 1997; 1997; pp. 688-691. [CrossRef]

26. Frodeman, R. Geo-Logic: Breaking Ground Between Philosophy and the Earth Sciences; SUNY Press: New York, NY, USA, 2003.

27. NASA Advisory Council; Earth System Sciences Committee. Earth System Science: A Closer View; National Aeronautics and Space Administration: Washington, DC, USA, 1988.

28. Steffen, W.; Richardson, K.; Rockström, J.; Schellnhuber, H.J.; Dube, O.P.; Dutreuil, S.; Lenton, T.M.; Lubchenco, J. The emergence and evolution of Earth System Science. Nat. Rev. Earth Environ. 2020, 1, 54-63. [CrossRef]

29. Edwards, M.G.; Alcaraz, J.M.; Cornell, S.E. Management education and earth system science: Transformation as if planetary boundaries mattered. Bus Soc. 2021, 60, 26-56. [CrossRef]

30. Lenton, T. Earth System Science: A Very Short Introduction; Oxford University Press: Oxford, UK, 2016.

31. Orion, N. An Earth Systems Curriculum Development Model. In Global Science Literacy; Mayer, V.J., Ed.; Springer: Dordrecht, The Netherlands, 2002; pp. 159-168. [CrossRef]

32. Steffen, W.; Rockström, J.; Richardson, K.; Lenton, T.M.; Folke, C.; Liverman, D.; Summerhayes, C.P.; Barnosky, A.D.; Cornell, S.E.; Crucifix, M.; et al. Trajectories of the earth system in the anthropocene. Proc. Natl. Acad. Sci. USA 2018, 115, 8252-8259. [CrossRef] [PubMed]

33. Mayer, V.J. Using the earth system for integrating the science curriculum. Sci. Educ. 1995, 79, 375-391. [CrossRef]

34. Jacobson, M.C.; Charlson, R.J.; Rodhe, H. Introduction: Biogeochemical Cycles as Fundamental Constructs for Studying Earth System Science and Global Change. In International Geophysics; Jacobson, M.C., Charlson, R.J., Rodhe, H., Orians, G.H., Eds.; Academic Press: Amsterdam, The Netherlands, 2000; pp. 3-13. [CrossRef]

35. Martin, R. Earth's Evolving Systems: The History of Planet Earth; Jones \& Bartlett Publishers: Burlington, MA, USA, 2013.

36. Ghilarov, A.M. Vernadsky's Biosphere Concept: An Historical Perspective. Q. Rev. Biol. 1995, 70, 193-203. [CrossRef]

37. Ortiz, J.D.; Jackson, R. Understanding Eunice Foote's 1856 experiments: Heat absorption by atmospheric gases. Notes and Records. R. Soc. J. Hist. Sci. 2020, 1-18. [CrossRef]

38. Lovelock, J. Gaia: A New Look at Life on Earth; Oxford University Press: Oxford, UK, 1979.

39. Kirchner, J.W. The Gaia hypothesis: Can it be tested? Rev. Geophys. 1989, 27, 223-235. [CrossRef]

40. Schellnhuber, H.J. 'Earth system' analysis and the second Copernican revolution. Nature 1999, 402, C19-C23. [CrossRef]

41. National Research Council. Earth System Science: Overview: A Program for Global Change; The National Academies Press: Washington, DC, USA, 1986. [CrossRef]

42. Goward, S.N.; Williams, D.L. Landsat and Earth Systems Science: Development of terrestrial monitoring. Photogramm. Eng. Remote Sens. 1997, 63, 887-900.

43. Scherer, H.H.; Holder, L.; Herbert, B. Student Learning of Complex Earth Systems: Conceptual Frameworks of Earth Systems and Instructional Design. J. Geosci. Educ. 2017, 65, 473-489. [CrossRef]

44. Mauser, W. Global Change Research in the Anthropocene: Introductory Remarks. In Earth System Science in the Anthropocene; Ehlers, E., Krafft, T., Eds.; Springer: Berlin, Germany, 2006; pp. 3-4. [CrossRef]

45. Donges, J.F.; Winkelmann, R.; Lucht, W.; Cornell, S.E.; Dyke, J.G.; Rockström, J.; Schellnhuber, H.J. Closing the loop: Reconnecting human dynamics to Earth System science. Anthr. Rev. 2017, 4, 151-157. [CrossRef]

46. Reid, W.V.; Chen, D.; Goldfarb, L.; Hackmann, H.; Lee, Y.T.; Mokhele, K.; Ostrom, E.; Raivio, K.; Rockström, J.; Schellnhuber, H.J.; et al. Earth System Science for Global Sustainability: Grand Challenges. Science 2010, 330, 916-917. [CrossRef] [PubMed]

47. Hoffman, M.; Barstow, D. Revolutionizing Earth System Science Education for the 21st Century: Report and Recommendations from a 50-State Analysis of Earth Science Education Standards; TERC: Cambridge, UK, 2007.

48. Oreskes, N. How earth science has become a social science. Hist. Soc. Res. 2015, 40, 246-270. [CrossRef]

49. Orion, N. A holistic approach for science education for all. Eurasia J. Math. Sci. Technol. 2007, 3, 111-118. [CrossRef]

50. Vasconcelos, C.; Ribeiro, T.; Cardoso, A.; Orion, N.; Ben-Shalom, R. The theoretical framework underpinning geoethical educational resources. In Teaching Geoethics: Resources for Higher Education; Vasconcelos, C., Schneider-Voß, S., Peppoloni, S., Eds.; U.Porto Edições: Porto, Portugal, 2020; pp. 19-29.

51. Mayer, V.J. Global science literacy: An earth system view. J. Res. Sci. Teach. 1997, 34, 101-105. [CrossRef]

52. Mayer, V.J.; Armstrong, R.E. What every 17-year old should know about planet earth: The report of a conference of educators and geoscientists. Sci. Educ. 1990, 74, 155-165. [CrossRef]

53. Orion, N.; Ault, C. Learning Earth Sciences. In Handbook of Research on Science Teaching and Learning; Abell, S., Lederman, N., Eds.; Lawrence Erlbaum Associates: Mahwah, NJ, USA, 2007; pp. 653-688.

54. Orion, N. Earth systems education and the development of environmental insight. In Geoscience Education: Indoor and Outdoor; Vasconcelos, C., Ed.; Springer: Cham, Switzerland, 2016; pp. 59-72.

55. Soltis, N.A.; McNeal, K.S.; Schnittka, C.G. Understanding undergraduate student conceptions about biogeochemical cycles and the earth system. J. Geosci. Educ. 2021, 69, 265-280. [CrossRef] 
56. Ben-Zvi-Assaraf, O.; Orion, N. Four case studies, six years later: Developing system thinking skills in junior high school and sustaining them over time. J. Res. Sci. Teach. 2010, 47, 1253-1280. [CrossRef]

57. Orion, N. A Model for the Development and Implementation of Field Trips as an Integral Part of the Science Curriculum. Sch. Sci. Math. 1993, 93, 325-331. [CrossRef]

58. Orion, N.; Hofstein, A. Factors that influence learning during a scientific field trip in a natural environment. J. Res. Sci. Teach. 1994, 31, 1097-1119. [CrossRef]

59. Orion, N.; Ben-Shalom, R.; Ribeiro, T.; Vasconcelos, C. Geoethics in field-trips: A global geoethics perspective. In Teaching Geoethics: Resources for Higher Education; Vasconcelos, C., Schneider-Voß, S., Peppoloni, S., Eds.; U.Porto Edições: Porto, Portugal, 2020; pp. 111-132.

60. Bodzin, A.M.; Anastasio, D. Using Web-based GIS for earth and environmental systems education. J. Geosci. Educ. 2006, 54, 295-300. [CrossRef]

61. Vasconcelos, C.; Schneider-Voß, S.; Peppoloni, S. Teaching Geoethics: Resources for Higher Education; U.Porto Edições: Porto, Portugal, 2020. [CrossRef]

62. Parra, G.; Hansmann, R.; Hadjichambis, A.C.; Goldman, D.; Paraskeva-Hadjichambi, D.; Sund, P.; Conti, D. Education for environmental citizenship and education for sustainability. In Conceptualizing Environmental Citizenship for 21st Century Education; Hadjichambis, A., Reis, P., Paraskeva-Hadjichambi, D., Cincera, J., Boeve-de Pauw, J., Gericke, N., Knippels, M.C., Eds.; Springer: Cham, Switzerland, 2020; pp. 149-160. [CrossRef]

63. Hadjichambis, A.; Reis, P. Introduction to the conceptualisation of environmental citizenship for twenty-first-century education. In Conceptualizing Environmental Citizenship for 21st Century Education; Hadjichambis, A., Reis, P., Paraskeva-Hadjichambi, D., Cincera, J., Boeve-de Pauw, J., Gericke, N., Knippels, M.C., Eds.; Springer: Cham, Switzerland, 2020; pp. 1-14. [CrossRef]

64. Vasconcelos, C. Geoscience Education: Indoor and Outdoor; Springer: Cham, Switzerland, 2016. [CrossRef]

65. Education 2030: Incheon Declaration and Framework for Action for the Implementation of Sustainable Development Goal 4 (ED-2016/WS/28). Available online: http:/ / uis.unesco.org/sites/default/files/documents/education-2030-incheon-frameworkfor-action-implementation-of-sdg4-2016-en_2.pdf (accessed on 1 June 2021).

66. Akin, S.; Calik, B. Students as change agents in the community: Developing active citizenship at schools. Educ. Sci. Theory Pract. 2017, 17, 809-834. [CrossRef] 